\title{
SCREENING OF PUTATIVE THERAPEUTIC CANDIDATES IN SUPERBUG (STAPHYLOCOCCUS AUREUS): A SYSTEMATIC IN SILICO APPROACH
}

\author{
KUNAL ZAVERI ${ }^{1}$, KIRANMAYI PATNALA ${ }^{2 *}$ \\ ${ }^{1}$ Department of Biochemistry and Bioinformatics, Institute of Science, GITAM University, Visakhapatnam, Andhra Pradesh, India. \\ ${ }^{2}$ Department of Biotechnology, Institute of Science, GITAM University, Visakhapatnam, Andhra Pradesh, India. \\ Email: kiranmayi.patnala@gmail.com
}

Received: 02 July 2016, Revised and Accepted: 11 July 2016

\section{ABSTRACT}

Objective: Staphylococcus aureus, a superbug and antibiotic resistant pathogen, is one of the most infection causing organism, ranging from skin allergies to severe lethal conditions. The prolonged use of different antibiotics and lack of optimal treatment over the antibiotic resistant species, led to the identification of new, better and promising therapeutic candidates.

Methods: A systematic in silico filtration process was employed, which includes subtractive channels and reverse vaccinology techniques

Results: Here, we report 12 possible drug targets and two vaccine candidates based on essentiality, non-human homolog, virulent and localization, commonly in all the strains. Further characterization studies such as pathway analysis, chokepoint and structure prediction revealed, two proteins as the best drug targets one being novel and the other druggable. Only one protein has shown the characteristic feature of vaccine candidate, having antigenic property and an IgG binding domain.

Conclusion: Two best drug targets were commonly identified in all the strains of $S$. aureus namely UDP-N-acetylmuramoyl-L-alanyl-D-glutamate--L-lysine ligase (MurE) and cell division protein FtsA, whereas the best common vaccine candidate includes Peptidoglycan binding protein. The therapeutic candidates reported in the present study might facilitate screening of new and better antimicrobial compounds, for an optimal treatment of $S$. aureus infections.

Keywords: Staphylococcus aureus, Drug target, Vaccine candidates, Subtractive proteomics, Reverse vaccinology.

(C) 2016 The Authors. Published by Innovare Academic Sciences Pvt Ltd. This is an open access article under the CC BY license (http://creativecommons. org/licenses/by/4. 0/) DOI: http://dx.doi.org/10.22159/ajpcr.2016.v9s2.13852

\section{INTRODUCTION}

Developing a novel drug against certain disease is a very intricate process with huge investments and also prolonged period of almost 12 15 years. The success of drug development mainly relies on the initial steps of drug discovery process which involves target identification and validation. Even clinically the failure of any drug mainly relies on whether it effectively acts on the target or on the safety issues of the drug [1]. Hence, target identification is very much essential, but the in vitro and in vivo processes are very costly and time-consuming which are eventually being replaced by modern computational methods. In the present study, we have taken the advantage of available proteomic data and other bioinformatics tools to screen the therapeutic candidates in a superbug Staphylococcus aureus.

S. aureus is a Gram-positive, facultative anaerobe, commensal, and opportunistic pathogen. It can survive in radical and adverse conditions such as temperature $7-48^{\circ} \mathrm{C}, \mathrm{pH} 4.00-10.00$ [2], high salt content, low $\mathrm{a}_{w}$ (water activity), and osmotic stress [3]. All these factors enable it to survive and colonize in anterior nares, gastrointestinal tract, groin, and axillae of humans [4]. The major transmission of $S$. aureus is by food poising [5] nosocomial routes and also from the community. It is capable of causing numerous diseases, ranging from minor skin infections to severe and lethal factors leading to death. These infections are most commonly treated by $\beta$-lactam antibiotics such as methicillin, penicillin, cephalosporins, and oxacillin, which mainly act on penicillin-binding proteins.

With a period, these bacteria have acquired methicillin resistance methicillin-resistant $S$. aureus (MRSA) that was first reported in 1961 [6] from the UK. The resistance was caused by mecA (methicillin resistance) gene acquired from distant species. This mecA gene is carried by Staphylococcal cassette chromosome mec mobile elements [7]. These strains have been evolved in two forms of infections hospital acquiredMRSA or nosocomial MRSA and community acquired-MRSA.
In the past decade, the mortality for drug resistance and antibiotics have very much increased by mainly six type of bacteria which are termed as Enterococcus faecium, S. aureus, Klebsiella pneumoniae, Acinetobacter baumannii, Pseudomonas aeruginosa, and Enterobacter species pathogens by rice [8]. Of these six pathogens, one of the most notorious is MRSA and accounts in the superbug hit list according to the US, centers for disease control and preventions 2013 report. Although the antibiotic strains have reported in the 1960's, the increase in mortality rate, and infections have gone pandemic in past two decades with major outbreaks caused by food poisoning at the US in 1990 [9], Brazil in 1998 [10], Japan in 2000 [11], Austria in 2006 [12], and Paraguay in 2007 [13], and the number of cases filed are represented in a graph (Fig. 1). The survival of organism at varied temperatures and in unhygienic places makes it much favorable to attack in developing countries. India being a developing country with tropic climate has made the bacteria endemic. About 13,975 MRSA cases in 2008 and 12,235 MRSA cases in 2009 were reported at 15 different Indian tertiary centers by (Indian network for surveillance of antimicrobial resistance) [14]. These pandemic situations are needed to be controlled by new and novel therapeutic alternatives.

In the present day, the MRSA is treated with the broad spectrum antibiotics in one or more combinations, which include glycopeptides such as vancomycin and teicoplanin [15], sulfa drugs and daptomycin [16]. These drugs are still not up to the mark to completely cure the infections and unfortunately $S$. aureus is gaining resistance even to these therapeutics. One such glycopeptide, vancomycin drug is now not susceptible over MRSA, and a new strain vancomycin-resistant $S$. aureus has been evolved [17]. The evolvement of different strains and subspecies of $S$. aureus requires common drug target and vaccine candidates for alternative treatments. In the present day, the scenario for research on identification of drug targets and vaccine candidates mainly relies on academic research as the pharmaceutics has ceased such research due to lack of profits [18]. 
In drug discovery, the major task is concerned in identifying potential drug targets and by bench work, it takes a lot of time and money. To avoid these hurdles, we have taken the advantage of modern in silico approach which includes, screening the proteome of the pathogen for essential, non-human homolog, and virulent proteins. Later, they were characterized based on their function, cellular localization, and metabolic pathways. Here, we report the common drug targets and vaccine candidates from around 14 strains of $S$. aureus and 30 strains of its subspecies $S$. aureus. Identification of common drug targets might help the physicians to treat the infection with ease, and a single vaccine candidate against various strains may protect us from infections.

\section{METHODS}

In the present study for identification of putative drug target and vaccine candidate in different strains of $S$. aureus, we have applied systematic in silico screening approach, with different filtering phases. The first phase of the filter is to screen the proteome with subtractive proteomics approach which includes identification of essential, nonhuman homologs, and virulent proteins. The second filter predicts whether the proteins may act as possible drug targets or vaccine candidates by subcellular localization. The proteins localized in cytoplasm, extracellular, membrane, and cell surface are possible drug targets and those who are localized only on the cell surface are possible vaccine candidates. The third filter includes screening the putative drug targets based on the pathway and chokepoint analysis and for vaccine candidates based on antigenicity, domains capable of binding immunoglobulin proteins, and epitome prediction. Final filtering phase is for broad spectrum analysis and for non-human gut flora. The complete workflow of subtractive proteomics and reverse vaccinology is depicted in Fig. 2.

\section{Data collection, databases, and tools employed}

The prime motto of our study was to identify the common drug targets and vaccine candidates from different strains of $S$. aureus and its subspecies $S$. aureus. The complete set of protein sequences in FASTA format was retrieved from NCBI database [19]. The essential protein analysis was carried out using database of essential genes (DEG) [20], non-human homologs protein sequences by Human-BLASTP [21], virulent proteins were predicted by VirulentPred [22], the subcellular localization of essential, non-human homolog with virulent nature were predicted by CELLO [23] and PSORT [24].

The proteins that are localized in any part of the cell are subjected for drug target analysis and further characterized. To those who are localized only on the cell surface are analyzed and characterized for vaccine candidates. The possible drug targets were analyzed for their involvement in any of the known pathways of $S$. aureus by KAAS (KEGG automated annotation system) [25]. Similarly, these proteins were compared with human metabolic pathways. The chokepoints were analyzed, and then druggability or novelty of the target was done by BLASTP against drugbank targets [26].

The proteins that are localized on cell surface were analyzed, for antigenic property by Vaxijen 2.0 [27], presence of transmembrane helices by TMHMM [28], identifying the domains that have the capability to bind to immune cells of humans by domain search against InterProScan [29], and finally characterizing the vaccine candidate by identifying the epitopes by SVMTriP [30]. Then, broad spectrum analysis and non-human gut flora analysis were carried out for drug target and vaccine candidate by BLASTP option from Human Microbiome Project [31,32].

\section{RESULTS AND DISCUSSION}

With the increase in mortality rates due to $S$. aureus infection and its capability to undergo resistance and emerging new varieties of resistant strains have pledged this study. This study includes identification of common drug targets and vaccine candidates as a source for alternative therapeutics. In 2001, two MRSA strains (N315 and Mu50) were sequenced [33] and deposited in NCBI for the first time since then about 42 more strains were sequenced by various groups and made available for the public. The availability of such a huge data of genome and proteome of approximately 44 strains of $S$. aureus has enabled us to carry out the study on identification of common therapeutics among them.

From NCBI protein database, the complete proteome of 14 S. aureus strains and $30 \mathrm{~S}$. aureus strains were retrieved. Of the 44 strains, 14 are annotated completely, 19 at contig level, and 11 are scaffolds. On an average genome size of every strain is about $2.8 \mathrm{Mb}$ with approximately 2,700 proteins in each strain. The protein sequences from all the strains were retrieved on or before $18^{\text {th }}$ August 2015, accounting to about 123,380 proteins.

The first phase of filtration in our study relies on the subtractive proteomic approach which is also known as differential genome display, proposed by Huynen et al. [34]. The main idea behind this paradigm was the fact that the parasitic microbes encode the lesser number of genes than that of free-living forms which make them pathogenic. The other point of this paradigm was that target must be a non-human homolog. During the course of time, this strategy was proposed; many scientists have successfully applied it, for mining the new therapeutic candidates. Some of the successful studies that included this strategy to establish novel therapeutics in Plasmodium falciparum [35], Mycoplasma hyopneumoniae [36], Clostridium perfringens [37], Salmonella typhi [38], Neisseria species [39], Aeromonas hydrophila [40], Helicobacter pylori [41], and in many other organisms.

In our study, we have first screened all the protein sequences against the proteins encoded by essential genes of $S$. aureus N315 and S. aureus NCTC8325 with the BLASTP parameters in DEG as E-value cutoff of $1 \mathrm{E}-05$ and BLOSUM62 matrix. The proteins that are encoded by a minimum set of genes play a crucial role in the survival of the organism and are essential genes [42,43], with this basis we have identified the essential proteins. In the essentiality screening process on an average, approximately 730 proteins were predicted to be essential from each strain and, on the whole, essential proteins account for 19,041. These essential genes were then filtered based on the non-human homolog, as the target protein from the microbe should not have a homology with that of humans, as to reduce the probability of the drug acting on the human proteins [44]. This filtration was done by subjecting the obtained sequences to BLASTP against the human proteome with a stringent selection of having no hits. A total of 1,022 proteins have shown no homology with that of the human proteome, which approximately corresponds to $20-23$ proteins per strain.

As the main goal of our study is to identify the common therapeutics against all the strains of $S$. aureus, we have manually mined the common and specific candidate proteins separately (Additional file (Tables S1-S3)). The virulence property for the common proteins from all

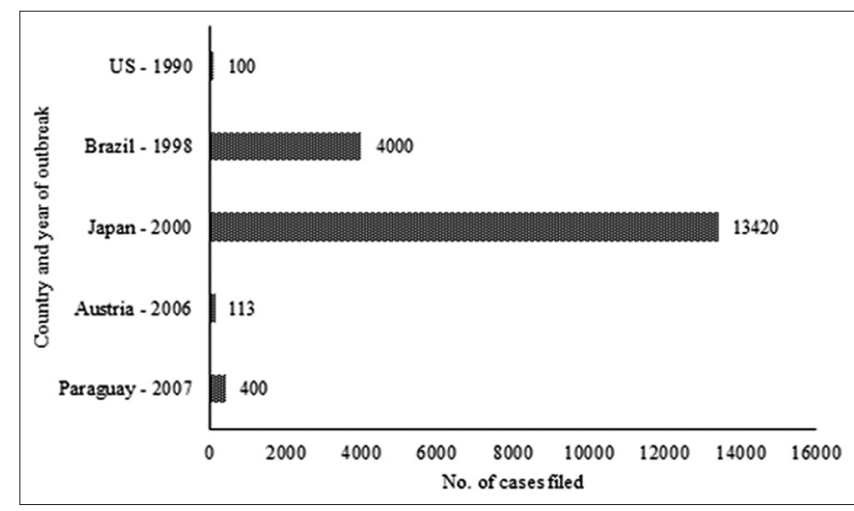

Fig. 1: Distribution of pandemics caused by Staphylococcus aureus in past decades 
strains was identified by VirulentPred. As the target protein must have virulence character to induce disease for alternative therapy against microbes [45]. This analysis indicated that 14 proteins have virulence property. The cellular localization was identified by CELLO and PSORT, which indicated that only two proteins are present on the cell surface of the protein and others either in the vicinity of cytoplasm, extracellular or in the nucleus. The overall filtration is depicted in Fig. 3, which indicates the extraction of a minimum number of possible therapeutics from a pool of huge proteome.

From the second filtration, the proteins that are localized in cytoplasm, extracellular, and membrane are considered as possible drug targets and that which resulted to be localized only on the cell surface are considered as possible vaccine candidates. Then, these proteins are further proceeded to respective filtration process as shown in Fig. 2. The possible drug targets and vaccine candidates filtered based on essentiality, non-human homolog, virulence, and cellular localization are listed in Table 1.

The possible drug targets are then subjected to KAAS server to identify their role in the known metabolic pathways of $S$. aureus. This analysis indicated that all the 12 proteins are involved in different pathways and some in common pathways. Among them, seven proteins are found to be enzymes. Enzymes are one of the best and second largest classes [46] of targets in drug discovery. The majority of the proteins were found to be having a role in peptidoglycan synthesis followed by cell cycle proteins, phosphotransferase system (PTS) proteins, and proteins involved in xenobiotic degradations (additional file 2 [Table S4]). Further, the enzymes were subject to chokepoint analysis, whether the

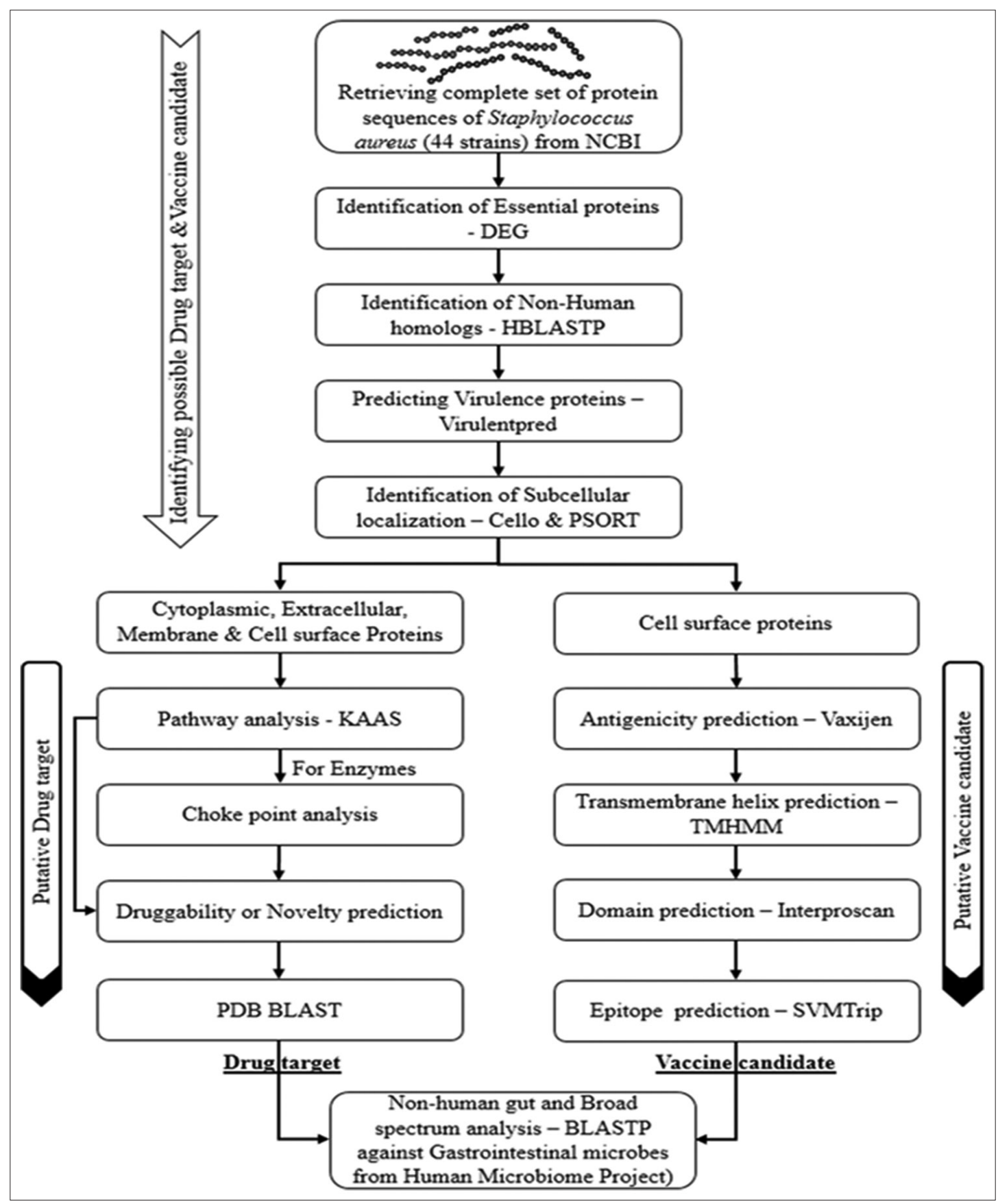

Fig. 2: Workflow for identification of drug targets and vaccine candidates 
enzyme consumes a specific substrate or produces a unique product and balances the reaction [47]. The chokepoint reactions are observed for three enzymes and the reactions of the enzymes are:

a. PTS alpha-glucoside transporter subunit IIBC

Protein EIIB N(pi)-phospho-L-histidine/cysteine + sugar = protein EIIB + sugar phosphate.

b. UDP-N-acetylglucosamine 1-carboxytransferase 1

Phosphoenolpyruvate + UDP-N-acetyl-alpha-D-glucosamine = phosphate + UDP-N-acetyl-3-0-(1-carboxyvinyl)-alpha-Dglucosamine.

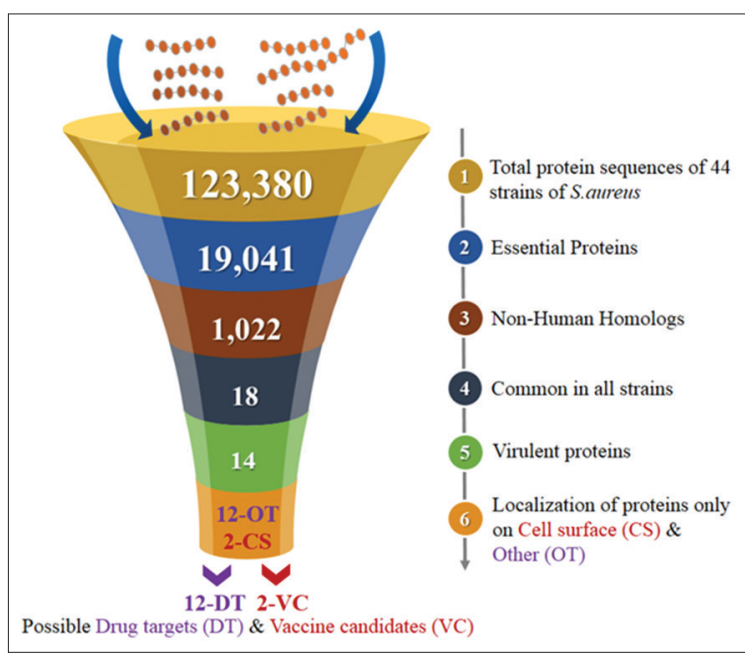

Fig. 3: Filtration for identification of possible therapeutic candidates c. UDP-N-acetylmuramoyl-L-alanyl-D-glutamate--L-lysine ligase ATP + UDP-N-acetyl-alpha-D-muramoyl-L-alanyl-D-glutamate + L-lysine = ADP + phosphate + UDP-N-acetyl-alpha-D-muramoyl-Lalanyl-gamma-D-glutamyl-L-lysine.

About five proteins were found to be druggable, and seven were found to be novel by drugbank analysis. The list of novel and druggable proteins are listed, with the drugs acting on the respective targets and the organism (Additional file 3 [Table S5]). Of the five druggable target proteins, four are enzymes. These set of 12 proteins were subjected to BLAST against Pluggable database (PDB) database to identify whether the targets have crystal structures. The 3-dimensional crystal structures of proteins define its biological activity and also define the topography of ligands interacting with the target proteins [48]. Hence, understanding the structure of proteins helps us in exploiting the selectivity and potency of the ligands. To only four protein targets the experimental structures are derived. Based on all the three filtrations, we could identify four common drug targets in all 44 strains of S. aureus (Table 2).

The two proteins that were found to be localized on the cell surface, $\mathrm{N}$-acetyl mannosaminyl transferase and peptidoglycan binding protein were analyzed for having antigenic property by Vaxijen. The $\mathrm{N}$-acetyl mannosaminyl transferase and peptidoglycan binding protein both have shown antigenic property score 0.4155 and 0.6982 , respectively, which is greater than that for threshold value (0.4) for bacterial models and hence specifying it to be a probable antigen. Protein to be a valid vaccine candidate it should not have more than three transmembrane helices and should have a domain that can bind to the immunoglobulins of the host (humans). The TMHMM predictions revealed that there are no transmembrane helices in $\mathrm{N}$-acetyl muramosaminly transferase, whereas peptidoglycan binding protein constitutes only one transmembrane helix ranging between 12 and 34 residues. The InterProScan have shown that

Table 1: List of proteins from primary and secondary filtration

\begin{tabular}{llllll}
\hline Serial number & Protein ID & Protein name & Length & Filtration & \\
\cline { 3 - 6 } & & & & Primary $^{\mathbf{a}}$ & Secondary $^{\mathbf{b}}$ \\
\hline 1 & & & 147 & Yes & Cytoplasmic \\
2 & WP_000050762.1 & PTS ascorbate transporter subunit IIA & 301 & Yes & Membrane \\
3 & WP_000184370.1 & Multispecies: Transglycosylase & Cell surface \\
4 & WP_000215388.1 & N-acetyl mannosaminyl transferase & 254 & Yes & Cytoplasmic \\
& WP_000340131.1 & UDP-N-acetylmuramoyl-L-alanyl & 494 & Yes & \\
5 & & -D-glutamate--L-lysine ligase & 439 & Yes & Extracellular \\
6 & WP_000342192.1 & Cell division protein FtsQ & 421 & Yes & Cytoplasmic \\
& WP_000358006.1 & UDP-N-acetylglucosamine 1 & & & \\
7 & & -carboxytransferase 1 & 470 & Yes & Cytoplasmic \\
8 & WP_000391033.1 & Cell division protein FtsA & 516 & Yes & Cell surface \\
9 & WP_000728751.1 & Peptidoglycan binding protein & 408 & Yes & Membrane \\
10 & WP_000787940.1 & Multispecies: Cell division protein FtsW & 691 & Yes & Extracellular \\
11 & WP_000919776.1 & Penicillin-binding protein 3 & 534 & Yes & Membrane \\
12 & WP_000991504.1 & PTS alpha-glucoside transporter subunit IIBC & 61 & Yes & Cytoplasmic \\
13 & WP_001123276.1 & Tautomerase & 66 & Yes & Extracellular \\
14 & WP_001125540.1 & Multispecies: 50S ribosomal protein L35 & 83 & Yes & Extracellular \\
\hline
\end{tabular}

Primarya: Proteins are essential, non-human homolog, and virulent. Secondary ${ }^{\mathrm{b}}$ : Localization of proteins

Table 2: Drug targets based on all three filtrations

\begin{tabular}{|c|c|c|c|c|c|c|}
\hline \multirow[t]{2}{*}{ Protein name } & \multicolumn{2}{|l|}{ Filtration } & \multirow[t]{2}{*}{ Pathway } & \multirow[t]{2}{*}{ Choke point } & \multirow[t]{2}{*}{ Druggability } & \multirow[t]{2}{*}{ PDB } \\
\hline & Primary $^{\mathrm{a}}$ & Secondary ${ }^{b}$ & & & & \\
\hline $\begin{array}{l}\text { UDP-N-acetylmuramoyl-L-alanyl } \\
\text {-D-glutamate--L-lysine ligase }\end{array}$ & Yes & Cytoplasmic & Peptidoglycan synthesis & Yes & Druggable & $4 \mathrm{C} 13$ \\
\hline Cell division protein FtsA & Yes & Cytoplasmic & Cell cycle & No & Novel & 3WQT \\
\hline Penicillin-binding protein 3 & Yes & Extracellular & Peptidoglycan synthesis & No & Druggable & 3VSK \\
\hline Tautomerase & Yes & Cytoplasmic & $\begin{array}{l}\text { Xylene, Benzoate, } \\
\text { Dioxin, and aromatic } \\
\text { degradation }\end{array}$ & No & Druggable & $2 \mathrm{X} 4 \mathrm{~K}$ \\
\hline
\end{tabular}


Table 3: Domains of peptidoglycan binding protein

\begin{tabular}{lllll}
\hline Peptidoglycan binding protein & Domain ID & Domain or repeat name & Amino acid residues & Biological process \\
\hline & IPR005877 & YSIRK Gram-positive signal peptide & $2-36$ & - \\
& IPR003132 & Protein A, Ig-binding domain & $37-327$ & $422-466$ \\
& IPR018392 & LysM domain & $475-516$ & - \\
& IPR019931 & LPXTG cell wall anchor domain & $326-421$ & Immunoglobulin binding \\
\hline
\end{tabular}

Table 4: Epitopes predicted in peptidoglycan binding protein

\begin{tabular}{llll}
\hline Rank & Epitope & Location & Score \\
\hline 1 & NLNEEQRNG & $174-182$ & 1.000 \\
2 & LKDDPSQSAN & $187-196$ & 0.878 \\
\hline
\end{tabular}

only peptidoglycan binding protein constitutes of immunoglobulin G (IgG) binding domain. Peptidoglycan binding protein is characterized with four different types of domains and one octapeptide repeat (Table 3) based on InterProScan analysis. Of these five domains, major part of the protein residues includes IgG binding domain ranging from 38 to 327 residues. Further, epitopes are also predicted (Table 4) by SVMTriP as they can bind to the host immune antibodies. A total of nine epitopes were predicted, of which first two epitope sequences have a high score and the residues fall in the IgG domain. This result indicates that peptidoglycan may be probable vaccine candidate for $S$. aureus infections. Finally, the broad spectrum analysis and non-human gut floral analysis was also carried out, and the results indicated that these sequences were not much conserved with other pathogens nor with any human gut flora. As these are non-human gut floral proteins, they can be considered as best therapeutic candidates.

In our study, we could identify the putative drug targets and vaccine candidates, which are majorly involved in three main pathways peptidoglycan synthesis, cell cycle, and xenobiotic degradation. The tautomerase protein plays an important role in xenobiotic degradation, but it consists of only 61 amino acid residues which make it unfavorable for further in silico studies. The other two pathways and their proteins are briefly discussed.

\section{Peptidoglycan synthesis}

The cytoplasm of bacteria being hypertonic to its surroundings and to resist from osmotic stress, a chain of identical molecules with semi-rigid nature called peptidoglycan layer is synthesized. The peptidoglycan layer is made up alternating of amino sugars, $\mathrm{N}$-acetylglucosamine, and N-acetylmuramic acid (NAM). These layers of NAM and NAG are interconnected by the peptide formed from NAM [49]. As the peptidoglycan layer protects the cell from stress, turgor pressure, and lysis, its integrity is, therefore, very much essential in the survival of bacteria [50]. The peptidoglycan layer is synthesized by series of enzymes and proteins which forms the best drug targets. According to Reed et al., the peptidoglycan can be synthesized by a minimum number of genes, but it loses it pathogenicity and resistance to antibiotics [50]. In our study, we have identified two targets which play key role in peptidoglycan synthesis, viz., UDP-N-acetylmuramoyl-L-alanyl-Dglutamate--L-lysine ligase (MurE) and penicillin-binding protein 3. MurE enzyme play an important role adding the L-lysine amino acid at the third position of the stem peptide, the lowered activity in in vivo of MurE, resulted in accumulation of MurNac and methicillin resistance was reduced [51], makes it the most favorable drug target. In the present study, we have observed some of the interesting features of MurE enzyme like it is essential for survival of the pathogen, it is nonhuman homolog, bearing virulent character, and plays an important role of adding lysine molecule to third position of stem peptide in the peptidoglycan pathway, which cannot be done by any other alternate enzymes. All these characteristic features make it one of the suitable drug targets to develop a novel therapeutics against staph infections.

\section{Cell cycle}

The series of steps that occur in a cell, for its division and replication (duplication), resulting into two daughter cells is known as cell cycle or cell division. In the cell division process, about 20 proteins form a multiprotein complex, which is known as divisome [52]. These proteins are assembled into the Z-ring structure by a divisome protein FtsZ. This ring structure helps the daughter cells to separate [53]. This structure is anchored to the cytoplasmic membrane by FtsA protein via C-terminal membranetargeting sequence [54]. FtsA possesses ATPase activity, as it belongs to the actin/MreB protein family [55]. In anticancer drug discovery, the major targets are cytokinesis or cell division proteins of eukaryotes. The drug resistance has also led the path for targeting the prokaryotic cell division proteins as antimicrobials. Some studies show that FtsZ can be the best target in drug-resistant organisms [56]. Here, we have identified cell division protein FtsA as the target protein which anchors the FtsZ ring complex. FtsA, showing ATPase activity, can be one of the attractive and best targets as there are many inhibitors that can act on ATPase [57].

\section{CONCLUSION}

The availability of complete proteome of different strains of $S$. aureus and by taking the advantage of current computational technologies, we have carried out the study. By employing the strategic, systematic in silico filtration process, the study reports common putative therapeutic candidates. The proteins filtered from the first phase, which satisfies the criteria of essentiality, non-human homolog, and virulence were the probable therapeutic candidates. The proteins that are contributed to be involved in pathways, chokepoints, having PDB structures, and mainly localized in the cytoplasm were characterized as the drug targets. Whereas the proteins that are localized on the cell surface having antigenic property, $\leq 3$ transmembranes, a domain with epitope that can bind host immunoglobulin were characterized as vaccine candidates. By this approach, two best drug targets were commonly identified in all the strains of $S$. aureus, namely, UDP-Nacetylmuramoyl-L-alanyl-D-glutamate--L-lysine ligase (MurE) and cell division protein FtsA, whereas the best common vaccine candidate includes peptidoglycan binding protein. MurE was found to be druggable target and FtsA to be a novel drug target. Further studies can define the probable compounds inhibiting the target molecules, which can be further used as alternative treatments. The systematic filtration process can further be employed on other pathogens of clinical interest, to identify rapidly and with ease the alternative therapeutic candidates.

\section{ACKNOWLEDGMENTS}

We would like to thank the Department of Biochemistry and Bioinformatics and Department of Biotechnology, Institute of Science, GITAM University, for providing the necessary facility to carry out the research work. Authors would also like to acknowledge the support provided by UGC project F.No.42-669/2013 (SR).

\section{REFERENCES}

1. Hughes JP, Rees S, Kalindjian SB, Philpott KL. Principles of early drug discovery. Br J Pharmacol 2011;162(6):1239-49.

2. Schmitt M, Schuler-Schmid U, Schmidt-Lorenz W. Temperature limits of growth, TNase and enterotoxin production of Staphylococcus aureus strains isolated from foods. Int J Food Microbiol 1990;11:1-19.

3. Rode TM, Møretrø T, Langsrud S, Holck A. Responses of Staphylococcus Aureus To Environmental Stresses. Stress Response of 
Foodborne microorganismsicroorganisms. 2012:509-46

4. Gordon RJ, Lowy FD. Pathogenesis of methicillin-resistant Staphylococcus aureus infection. Clin Infect Dis 2008;46 Suppl 5:S350-9.

5. Argudín MÁ, Mendoza MC, Rodicio MR. Food poisoning and Staphylococcus aureus enterotoxins. Toxins (Basel) 2010;2(7):1751-73.

6. Jevons MP. "Celbenin" - resistant staphylococci. Br Med J. BMJ Group; 1961. p. 124. Available from: http://www.ncbi.nlm.nih.gov/ pmc/articles/PMC1952888/.

7. Hiramatsu K, Cui L, Kuroda M, Ito T. The emergence and evolution of methicillin-resistant Staphylococcus aureus. Trends Microbiol 2001;9(10):486-93.

8. Rice LB. Federal funding for the study of antimicrobial resistance in nosocomial pathogens: No eskape. J Infect Dis 2008;197(8):1079-81.

9. Richards MS, Rittman M, Gilbert TT, Opal SM, DeBuono BA, Neill $\mathrm{RJ}$, et al. Investigation of a staphylococcal food poisoning outbreak in a centralized school lunch program. Public Health Rep 1993;108(6):765-71.

10. Do Carmo LS, Cummings C, Linardi VR, Dias RS, De Souza JM, De Sena MJ, et al. A case study of a massive staphylococcal food poisoning incident. Foodborne Pathog Dis 2004;1(4):241-6.

11. Asao T, Kumeda Y, Kawai T, Shibata T, Oda H, Haruki K, et al. An extensive outbreak of staphylococcal food poisoning due to low-fa milk in Japan: Estimation of enterotoxin A in the incriminated milk and powdered skim milk. Epidemiol Infect 2003;130(1):33-40.

12. Schmid D, Gschiel E, Mann M, Huhulescu S, Ruppitsch W, Böhm G, et al. Outbreak of acute gastroenteritis in an Austrian boarding school, September, 2006. European Centre for Disease Prevention and Control (ECDC) - Health Comunication Unit; 2007. Available from: http:// www.eurosurveillance.org/ViewArticle.aspx?ArticleId=692.

13. Weiler N, Leotta GA, Zárate MN, Manfredi E, Alvarez ME, Rivas M Foodborne outbreak associated with consumption of ultrapasteurized milk in the Republic of Paraguay. Rev Argent Microbiol 2011;43(1):33-6.

14. Joshi S, Ray P, Manchanda V, Bajaj J, Gautam V, Goswami P, et al. Methicillin resistant Staphylococcus aureus (MRSA) in India: Prevalence \& susceptibility pattern. Indian J Med Res 2013;137:363-9.

15. Moellering RC Jr. Vancomycin: A 50-year reassessment. Clin Infect Dis 2006;42 Suppl 1:S3-4.

16. Shoemaker DM, Simou J, Roland WE. A review of daptomycin for injection (cubicin) in the treatment of complicated skin and skin structure infections. Ther Clin Risk Manag 2006;2(2):169-74.

17. Sieradzki K, Tomasz A. Inhibition of cell wall turnover and autolysis by vancomycin in a highly vancomycin-resistant mutant of Staphylococcus aureus. J Bacteriol 1997;179(8):2557-66.

18. Projan SJ. Why is big pharma getting out of antibacterial drug discovery? Curr Opin Microbiol 2003;6(5):427-30.

19. Tatusova T, Ciufo S, Fedorov B, O’Neill K, Tolstoy I. RefSeq microbial genomes database: New representation and annotation strategy. Nucleic Acids Res 2014;42:D553-9.

20. Luo H, Lin Y, Gao F, Zhang CT, Zhang R. DEG 10, an update of the database of essential genes that includes both protein-coding genes and noncoding genomic elements. Nucleic Acids Res 2014;42:D574-80.

21. Altschul SF, Gish W, Miller W, Myers EW, Lipman DJ. Basic local alignment search tool. J Mol Biol 1990;215(3):403-10.

22. Garg A, Gupta D. VirulentPred: A SVM based prediction method for virulent proteins in bacterial pathogens. BMC Bioinformatics 2008;9:62.

23. $\mathrm{Yu} \mathrm{C}$, Chen $\mathrm{Y}$, Lu C, Hwang J. Prediction of protein subcellular localization. Amino Acids 2006;651:643-51.

24. Yu NY, Wagner JR, Laird MR, Melli G, Rey S, Lo R, et al. PSORTb 3.0: Improved protein subcellular localization prediction with refined localization subcategories and predictive capabilities for all prokaryotes. Bioinformatics 2010;26(13):1608-15.

25. Moriya Y, Itoh M, Okuda S, Yoshizawa AC, Kanehisa M. KAAS An automatic genome annotation and pathway reconstruction server. Nucleic Acids Res 2007;35:W182-5.

26. Wishart DS, Knox C, Guo AC, Shrivastava S, Hassanali M, Stothard P, et al. Drugbank: A comprehensive resource for in silico drug discovery and exploration. Nucleic Acids Res 2006;34:D668-72.

27. Doytchinova IA, Flower DR. VaxiJen: A server for prediction of protective antigens, tumour antigens and subunit vaccines. BMC Bioinformatics 2007;8:4

28. Möller S, Croning MD, Apweiler R. Evaluation of methods for the prediction of membrane spanning regions. Bioinformatics 2001;17(7):646-53.

29. Mitchell A, Chang HY, Daugherty L, Fraser M, Hunter S, Lopez R, et al. The interpro protein families database: The classification resource after 15 years. Nucleic Acids Res 2015;43:D213-21.

30. Yao B, Zhang L, Liang S, Zhang C. SVMTriP: A method to predict antigenic epitopes using support vector machine to integrate tri-peptide similarity and propensity. PLoS One 2012;7(9):e45152.

31. Human Microbiome Project Consortium. A framework for human microbiome research. Nature 2012;486(7402):215-21.

32. Human Microbiome Project Consortium. Structure, function and diversity of the healthy human microbiome. Nature 2012;486(7402):207-14.

33. Kuroda M, Ohta T, Uchiyama I, Baba T, Yuzawa H, Kobayashi I, et al. Whole genome sequencing of meticillin-resistant Staphylococcus aureus. Lancet 2001;357(9264):1225-40.

34. Huynen MA, Diaz-Lazcoz Y, Bork P. Differential genome display. Trends Genet 1997;13(10):389-90.

35. Ludin P, Woodcroft B, Ralph SA, Mäser P. In silico prediction of antimalarial drug target candidates. Int J Parasitol Drugs drug Resist 2012;2:191-9.

36. Damte D, Suh JW, Lee SJ, Yohannes SB, Hossain MA, Park SC. Putative drug and vaccine target protein identification using comparative genomic analysis of KEGG annotated metabolic pathways of Mycoplasma hyopneumoniae. Genomics 2013;102(1):47-56.

37. Chhabra G, Sharma P, Anant A, Deshmukh S, Kaushik H, Gopal K, et al. Identification and modeling of a drug target for Clostridium perfringens SM101. Bioinformation 2010;4(7):278-89.

38. Rathi B, Sarangi AN, Trivedi N. Genome subtraction for novel target definition in Salmonella typhi. Bioinformation 2009;4(4):143-50.

39. Narayan Sarangi A, Aggarwal R, Rahman Q, Trivedi N. Subtractive genomics approach for in silico identification and characterization of novel drug targets in Neisseria meningitidis serogroup B. J Comput Sci Syst Biol 2009;2:255-8.

40. Sharma V, Gupta P, Dixit A. In silico identification of putative drug targets from different metabolic pathways of Aeromonas hydrophila. In Silico Biol 2008;8(3-4):331-8

41. Dutta A, Singh SK, Ghosh P, Mukherjee R, Mitter S, Bandyopadhyay D. In silico identification of potential therapeutic targets in the human pathogen Helicobacter pylori. In Silico Biol 2006;6(1-2):43-7.

42. Koonin EV. How many genes can make a cell: The minimal-gene-set concept. Annu Rev Genomics Hum Genet 2000;1:99-116.

43. Gerdes S, Edwards R, Kubal M, Fonstein M, Stevens R, Osterman A Essential genes on metabolic maps. Curr Opin Biotechnol 2006;17(5):448-56.

44. Duffield M, Cooper I, McAlister E, Bayliss M, Ford D, Oyston P. Predicting conserved essential genes in bacteria: In silico identification of putative drug targets. Mol Biosyst 2010;6(12):2482-9.

45. Cegelski L, Marshall GR, Eldridge GR, Hultgren SJ. The biology and future prospects of antivirulence therapies. Nat Rev Microbiol 2008;6(1):17-27.

46. Rask-Andersen M, Almén MS, Schiöth HB. Trends in the exploitation of novel drug targets. Nat Rev Drug Discov 2011;10(8):579-90.

47. Yeh I, Hanekamp T, Tsoka S, Karp PD, Altman RB. Computational analysis of Plasmodium falciparum metabolism: Organizing genomic information to facilitate drug discovery. Genome Res 2004;14(5):917-24.

48. Campbell SF. Science, art and drug discovery: A personal perspective Clin Sci (Lond) 2000;99(4):255-60.

49. Meroueh SO, Bencze KZ, Hesek D, Lee M, Fisher JF, Stemmler TL, et al. Three-dimensional structure of the bacterial cell wall peptidoglycan. Proc Natl Acad Sci U S A 2006;103(12):4404-9.

50. Reed P, Atilano ML, Alves R, Hoiczyk E, Sher X, Reichmann NT, et al. Staphylococcus aureus survives with a minimal peptidoglycan synthesis machine but sacrifices virulence and antibiotic resistance. PLoS Pathog 2015;11(5):e1004891.

51. Ruane KM, Lloyd AJ, Fülöp V, Dowson CG, Barreteau H, Boniface A, et al. Specificity determinants for lysine incorporation in Staphylococcus aureus peptidoglycan as revealed by the structure of a MurE enzyme ternary complex. J Biol Chem 2013;288(46):33439-48.

52. Aarsman ME, Piette A, Fraipont C, Vinkenvleugel TM, NguyenDistèche M, den Blaauwen T. Maturation of the Escherichia coli divisome occurs in two steps. Mol Microbiol 2005;55(6):1631-45.

53. Lutkenhaus J, Addinall SG. Bacterial cell division and the Z ring. Annu Rev Biochem 1997;66:93-116.

54. Pichoff S, Lutkenhaus J. Tethering the $\mathrm{Z}$ ring to the membrane through a conserved membrane targeting sequence in FtsA. Mol Microbiol 2005;55(6):1722-34.

55. Bork P, Sander C, Valencia A. An ATPase domain common to prokaryotic cell cycle proteins, sugar kinases, actin, and hsp70 heat shock proteins. Proc Natl Acad Sci U S A 1992;89(16):7290-4

56. Ojima I, Kumar K, Awasthi D, Vineberg JG. Drug discovery targeting cell division proteins, microtubules and FtsZ. Bioorg Med Chem 2014;22(18):5060-77.

57. Chène P. ATPases as drug targets: Learning from their structure. Nat Rev Drug Discov 2002;1(9):665-73. 
Table S1: Common essential and non-human homolog proteins in all strains

\begin{tabular}{|c|c|c|c|c|}
\hline $\begin{array}{l}\text { Serial } \\
\text { number }\end{array}$ & Strain & Protein ID & Protein Name & Length \\
\hline 1 & $\begin{array}{l}\text { In all the } 44 \text { strains of } \\
\text { Staphylococcus aureus }\end{array}$ & WP_000050762.1 & PTS ascorbate transporter subunit IIA & 147 \\
\hline 2 & & WP_000145499.1 & Multispecies: Hypothetical protein & 339 \\
\hline 3 & & WP_000184370.1 & Multispecies: Transglycosylase & 301 \\
\hline 4 & & WP_000244865.1 & Multispecies: Septation ring formation regulator EzrA & 564 \\
\hline 5 & & WP_000340131.1 & $\begin{array}{l}\text { UDP-N-acetylmuramoyl-L-alanyl } \\
\text {-D-glutamate--L-lysine ligase }\end{array}$ & 494 \\
\hline 6 & & WP_000342192.1 & Cell division protein FtsQ & 439 \\
\hline 7 & & WP_000358006.1 & UDP-N-acetylglucosamine 1-carboxytransferase 1 & 421 \\
\hline 8 & & WP_000391033.1 & Cell division protein FtsA & 470 \\
\hline 9 & & WP_000409682.1 & Multispecies: Ribonuclease P protein component & 115 \\
\hline 10 & & WP_000533493.1 & Helicase DnaB & 466 \\
\hline 11 & & WP_000725225.1 & Multispecies: Hypothetical protein & 255 \\
\hline 12 & & WP_000787940.1 & Multispecies: Cell division protein FtsW & 408 \\
\hline 13 & & WP_000803157.1 & Nuclease SbcCD subunit C & 1009 \\
\hline 14 & & WP_000834090.1 & Hypothetical protein & 476 \\
\hline 15 & & WP_000876756.1 & Multispecies: Transcriptional regulator & 250 \\
\hline 16 & & WP_000919776.1 & Penicillin-binding protein 3 & 691 \\
\hline 17 & & WP_000991504.1 & PTS alpha-glucoside transporter subunit IIBC & 534 \\
\hline 18 & & WP_001123276.1 & Tautomerase & 61 \\
\hline 19 & & WP_001125540.1 & Multispecies: 50S ribosomal protein L35 & 66 \\
\hline 20 & & WP_001125619.1 & $\mathrm{N}$-acetylmuramoyl-L-alanine amidase & 619 \\
\hline 21 & & WP_001274017.1 & Multispecies: 30 S ribosomal protein S20 & 83 \\
\hline
\end{tabular}

S. aureus: Staphylococcus aureus

Table S2: Common essential and non-human homolog proteins in some of the strains

\begin{tabular}{|c|c|c|c|}
\hline Strain & Protein ID & Protein name & Length \\
\hline BSAR706/8987 & CPQ78240.1 & AmrA & 476 \\
\hline BSAR863/9061 & CPJ34910.1 & AmrA & 476 \\
\hline M0408 & WP_000145497.1 & Chitinase & 339 \\
\hline SA3-LAU & WP 029549721.1 & Chitinase & 339 \\
\hline 930918-3 & WP_001077826.1 & Cobalt $\mathrm{ABC}$ transporter permease & 277 \\
\hline M21126 & WP_031787615.1 & Cobalt ABC transporter permease & 277 \\
\hline RF122 & WP_000046022.1 & Delta-hemolysin & 26 \\
\hline 21262 & WP_000046022.1 & Delta-hemolysin & 26 \\
\hline 21269 & WP_000046023.1 & Delta-hemolysin & 26 \\
\hline LGA251 & WP_000046022.1 & Delta-hemolysin & 26 \\
\hline ED1333 & WP_000046023.1 & Delta-hemolysin & 26 \\
\hline M0406 & WP_000473653.1 & $\begin{array}{l}\text { Glucose-specific phosphotransferase } \\
\text { enzyme IIA component }\end{array}$ & 166 \\
\hline M1216 & WP_000473651.1 & $\begin{array}{l}\text { Glucose-specific phosphotransferase } \\
\text { enzyme IIA component }\end{array}$ & 166 \\
\hline MR1 & WP_000473653.1 & $\begin{array}{l}\text { Glucose-specific phosphotransferase } \\
\text { enzyme IIA component }\end{array}$ & 166 \\
\hline VRS2 & WP_000473653.1 & $\begin{array}{l}\text { Glucose-specific phosphotransferase } \\
\text { enzyme IIA component }\end{array}$ & 166 \\
\hline 21310 & WP_000473653.1 & $\begin{array}{l}\text { Glucose-specific phosphotransferase } \\
\text { enzyme IIA component }\end{array}$ & 166 \\
\hline 21334 & WP_000473653.1 & $\begin{array}{l}\text { Glucose-specific phosphotransferase } \\
\text { enzyme IIA component }\end{array}$ & 166 \\
\hline CM05 & WP_000473653.1 & $\begin{array}{l}\text { Glucose-specific phosphotransferase } \\
\text { enzyme IIA component }\end{array}$ & 166 \\
\hline JH9 & WP_000473653.1 & $\begin{array}{l}\text { Glucose-specific phosphotransferase } \\
\text { enzyme IIA component }\end{array}$ & 166 \\
\hline N315 & WP_000473653.1 & $\begin{array}{l}\text { Glucose-specific phosphotransferase } \\
\text { enzyme IIA component }\end{array}$ & 166 \\
\hline M0408 & WP_000736790.1 & Glycyl-glycine endopeptidase LytM & 316 \\
\hline SF1585 & WP_000736790.1 & Glycyl-glycine endopeptidase LytM & 316 \\
\hline TW20 & WP_000736790.1 & Glycyl-glycine endopeptidase LytM & 316 \\
\hline 21202 & WP_000736800.1 & Glycyl-glycine endopeptidase LytM & 316 \\
\hline MRSA252 & WP_000736790.1 & Glycyl-glycine endopeptidase LytM & 316 \\
\hline S2398 & WP_000736790.1 & Glycyl-glycine endopeptidase LytM & 316 \\
\hline 21262 & WP_000271552.1 & Holliday junction DNA helicase RuvA & 200 \\
\hline M21126 & WP_000271553.1 & $\begin{array}{l}\text { Multispecies: Holliday junction DNA } \\
\text { helicase RuvA }\end{array}$ & 200 \\
\hline SA3-LAU & WP_029549861.1 & Polysaccharide extrusion protein & 476 \\
\hline SA083 & WP_043044852.1 & Polysaccharide extrusion protein & 476 \\
\hline
\end{tabular}


Table S2: (Continued)

\begin{tabular}{|c|c|c|c|}
\hline Strain & Protein ID & Protein name & Length \\
\hline RF122 & WP_000505013.1 & Protein GlcT & 283 \\
\hline 21262 & WP_000505013.1 & Protein GlcT & 283 \\
\hline 21269 & WP_000505012.1 & Protein glct & 283 \\
\hline LGA251 & WP 000505013.1 & Protein glct & 283 \\
\hline ED1333 & WP_000505013.1 & Protein glct & 283 \\
\hline 21262 & WP_001140868.1 & Pyrophosphatase & 309 \\
\hline JKD6159 & WP_001140868.1 & Pyrophosphatase & 309 \\
\hline N315 & WP_001283057.1 & RNA polymerase sigma factor SigA & 368 \\
\hline M0406 & WP_001041111.1 & RNA polymerase sigma factor SigB & 256 \\
\hline MR1 & WP_001041111.1 & RNA polymerase sigma factor SigB & 256 \\
\hline VRS2 & WP 001041111.1 & RNA polymerase sigma factor SigB & 256 \\
\hline CM05 & WP_001041111.1 & RNA polymerase sigma factor SigB & 256 \\
\hline JH9 & WP_001041111.1 & RNA polymerase sigma factor SigB & 256 \\
\hline N315 & WP_001041111.1 & RNA polymerase sigma factor SigB & 256 \\
\hline BSAR863/9061 & CPI777587.1 & Secretory antigen & 255 \\
\hline BSAR706/8987 & CPQ65358.1 & Secretory antigen & 255 \\
\hline S. aureus 1 & WP_047425989.1 & Secretory antigen precursor & 168 \\
\hline S. aureus 2 & WP_047549686.1 & Secretory antigen precursor & 168 \\
\hline BSAR863/9061 & CPI555316.1 & Secretory antigen precursor & 269 \\
\hline BSAR706/8987 & CPQ38910.1 & Secretory antigen precursor & 269 \\
\hline A9635 & WP_000143415.1 & Sensor histidine kinase & 295 \\
\hline 21252 & WP_000143414.4 & Sensor histidine kinase & 295 \\
\hline 21202 & WP 000143414.4 & Sensor histidine kinase & 295 \\
\hline BSAR863/9061 & CPI66829.1 & Staphylococcal accessory regulator A & 250 \\
\hline BSAR706/8987 & CPQ78533.1 & Staphylococcus accessory regulator a & 250 \\
\hline M21126 & WP_031787470.1 & Teichoic acid biosynthesis protein $b$ & 366 \\
\hline S. aureus 1 & WP_047427601.1 & Teichoic and biosynthesis protein $b$ & 367 \\
\hline M0406 & WP_001557393.1 & Transposase & 30 \\
\hline MR1 & WP_001557393.1 & Transposase & 30 \\
\hline VRS2 & WP_001557393.1 & Transposase & 30 \\
\hline 21193 & WP_001557393.1 & Transposase & 30 \\
\hline CM05 & WP_001557393.1 & Transposase & 30 \\
\hline JH9 & WP_001557393.1 & Transposase & 30 \\
\hline N315 & WP_001557393.1 & Transposase & 30 \\
\hline BSAR863/9061 & CPĪ58700.1 & Uroporphyrin-III C-methyltransferase & 118 \\
\hline BSAR706/8987 & CPQ40681.1 & Uroporphyrin-III C-methyltransferase & 118 \\
\hline
\end{tabular}

S. aureus: Staphylococcus aureus

Table S3: Common essential and non-human homolog proteins in specific strains

\begin{tabular}{llll}
\hline Strain & Protein ID & Protein name & Length \\
\hline BSAR706/8987 & CPQ99501.1 & 3-oxoacyl-ACP syntase & 69 \\
NCTC8325 & YP_498671.1 & Accessory regulator-like protein & 250 \\
1189-97 & WP_050809366.1 & ATPase & 651 \\
BSAR706/8987 & CPQ29832.1 & Cell division protein FtsI & 691 \\
S. aureus 1 & WP_047423896.1 & Chromosome partitioning protein ParB & 281 \\
BSAR706/8987 & CPR09455.1 & Cof family hydrolase & 46 \\
M21126 & WP_031787927.1 & Histidine kinase & 370 \\
M21126 & WP_031786986.1 & Homoserine kinase & 304 \\
NCTC8325 & YP_501337.1 & LysM domain-containing protein & 255 \\
21202 & WP_001140876.1 & Manganese-dependent inorganic pyrophosphatase & 309 \\
M21126 & WP_000584622.1 & Multispecies: DNA double-strand break repair rad50 atpase & 978 \\
TW20 & WP_000135455.1 & Phage tail tape measure protein & 2757 \\
M0408 & WP_001573496.1 & Potassium-transporting ATPase A chain 1 & 438 \\
S2398 & WP_033845065.1 & Staphyloxanthin biosynthesis protein & 297 \\
M1216 & WP_006190740.1 & Sucrose operon repressor & 316 \\
BSAR706/8987 & CPR08741.1 & Transmembrane component of general energizing module of ECF transporters & 43 \\
930918-3 & WP_050346508.1 & UDP kinase & 90 \\
\hline
\end{tabular}

\footnotetext{
S. aureus: Staphylococcus aureus
} 
Table S4: Possible drug targets involved in different pathways

\begin{tabular}{|c|c|c|c|}
\hline Protein name & Pathway ID & Pathway & Enzyme (E.C) \\
\hline \multirow[t]{2}{*}{ PTS ascorbate transporter subunit IIA } & K000053 & Ascorbate and aldarate metabolism & 2.7.1.69 \\
\hline & K002060 & Phosphotransferase system & \\
\hline Multispecies: Transglycosylase & K000550 & Peptidoglycan synthesis & 2.4.2.48 \\
\hline UDP-N-acetylmuramoyl-L-alanyl-D-glutamate--L-lysine ligase & K000550 & Peptidoglycan synthesis & 6.3.2.7 \\
\hline cell division protein FtsQ & K004112 & Cell cycle & - \\
\hline \multirow[t]{2}{*}{ UDP-N-acetylglucosamine 1 -carboxytransferase 1} & KO00520 & Amino sugar and nucleotide sugar metabolism & 2.5.1.7 \\
\hline & K000550 & Peptidoglycan synthesis & \\
\hline multispecies: Cell division protein FtsW & K004112 & Cell cycle & - \\
\hline \multirow[t]{2}{*}{ penicillin-binding protein 3} & K001501 & $\beta$-lactam resistance & 2.4.1.129 \\
\hline & K000550 & Peptidoglycan synthesis & \\
\hline \multirow[t]{2}{*}{ PTS alpha-glucoside transporter subunit IIBC } & K000010 & Glycolysis/glycogenesis & 2.7.1.69 \\
\hline & K002060 & Phosphotransferase system & \\
\hline \multirow[t]{3}{*}{ Tautomerase } & K000622 & Xylene degradation & 5.3.2.6 \\
\hline & K000362 & Benzoate degradation & \\
\hline & K000621 & Dioxin degradation & \\
\hline Multispecies: 50S ribosomal protein L35 & K003010 & Ribosome & - \\
\hline Multispecies: 30S ribosomal protein S20 & K003010 & Ribosome & - \\
\hline
\end{tabular}

Table S5: Druggability analysis of identified drug targets

\begin{tabular}{|c|c|c|c|}
\hline Protein name & Druggability & Druggable against organism & Drug \\
\hline PTS ascorbate transporter subunit IIA & Novel & - & - \\
\hline Multispecies: Transglycosylase & Novel & - & - \\
\hline UDP-N-acetylmuramoyl-L-alanyl-D & Druggable & Escherichia coli (strain K12) & Uridine-5'-diphosphate-N-Acetylmuramoyl \\
\hline \multirow[t]{3}{*}{-glutamate--L-lysine ligase } & & & -L-alanine-D-glutamate ${ }^{(\mathrm{E})}$ \\
\hline & & & 2,6-diaminopimelic $\operatorname{acid}^{(\mathrm{E})}$ \\
\hline & & & Lysine Nz-carboxylic acid(E) \\
\hline Cell division protein FtsQ & Novel & - & - \\
\hline UDP-N-acetylglucosamine 1 & Druggable & Escherichia coli (strain K12) & Fosfomycin ${ }^{(A)}$ \\
\hline \multicolumn{4}{|l|}{-carboxytransferase 1} \\
\hline Cell division protein FtsA & Novel & - & - \\
\hline Multispecies: Cell division protein FtsW & Novel & - & - \\
\hline -binding protein 3 & Druggable & $\begin{array}{l}\text { Streptococcus pneumoniae } \\
\text { serotype } 4 \text { (strain ATCC BAA-334/ } \\
\text { TIGR4) }\end{array}$ & $\begin{array}{l}\text { Cloxacillin }^{(\mathrm{A})} ; \text { Cefprozil }^{(\mathrm{A})} \\
\text { faropenem medoxomil }^{(\mathrm{I})}\end{array}$ \\
\hline PTS alpha-glucoside transporter subunit IIBC & Novel & - & - \\
\hline \multirow[t]{2}{*}{ Multispecies: 30S ribosomal protein S20 } & Druggable & Thermus thermophilus & 2-methylthio-n6-isopentenyl \\
\hline & & (strain HB8/ATCC 27634/DSM 579) & -adenosine-5'-monophosphate ${ }^{(\mathrm{E})}$ \\
\hline
\end{tabular}

${ }^{(A)}$ Approved ${ }^{(I)}$ Investigating ${ }^{(\mathrm{E})}$ Experimental. E. coli: Escherichia coli, S. pneumoniae: Streptococcus pneumoniae, P. putida: Pseudomonas putida, T. thermophilus: Thermus thermophilus 